\title{
Lung-Clearance Classification of Radionuclides in Calcined Phosphate Rock Dust
}
D. R. Kalkwarf
P. O. Jackson

August 1984

\author{
Prepared for \\ the U.S. Environmental Protection Agency \\ under a Related Services Agreement \\ with the U.S. Department of Energy \\ Contract DE-AC06-76LO 1830
}

Pacific Northwest Laboratory Operated for the U.S. Department of Energy by Battelle Memorial Institute 


\section{DISCLAIMER}

This report was prepared as an account of work sponsored by an agency of the United States Government. Neither the United States Government nor any agency thereof, nor any of their employees, makes any warranty, express or implied, or assumes any legal liability or responsibility for the accuracy, completeness, or usefulness of any information, apparatus, product, or process disclosed, or represents that its use would not infringe privately owned rights. Reference herein to any specific commercial product, process, or service by trade name, trademark, manufacturer, or otherwise, does not necessarily constitute or imply its endorsement, recommendation, or favoring by the United States Government or any agency thereof. The views and opinions of authors expressed herein do not necessarily state or reflect those of the United States Government or any agency thereof.

\section{PACIFIC NORTHWEST LABORATORY operated by \\ BATTELLE \\ for the \\ UNITED STATES DEPARTMENT OF ENERGY \\ under Contract DE-AC06-76RLO 1830}

\begin{tabular}{|c|c|}
\hline \multicolumn{2}{|c|}{ Printed in the United States of America } \\
\hline \multirow{2}{*}{\multicolumn{2}{|c|}{$\begin{array}{l}\text { Available from } \\
\text { National Technical Information Service }\end{array}$}} \\
\hline & \\
\hline \multicolumn{2}{|c|}{ United States Department of Commerce } \\
\hline \multicolumn{2}{|c|}{5285 Port Royal Road } \\
\hline \multicolumn{2}{|c|}{ Springfield, Virginia 22161} \\
\hline \multirow{2}{*}{\multicolumn{2}{|c|}{$\begin{array}{l}\text { NTIS Price Codes } \\
\text { Microfiche A01 }\end{array}$}} \\
\hline & \\
\hline \multicolumn{2}{|c|}{ Printed Copy } \\
\hline & \\
\hline Pages & Codes \\
\hline $001-025$ & $\mathrm{~A} 02$ \\
\hline 026-050 & $\mathrm{A} 03$ \\
\hline $051-075$ & $\mathrm{~A} 04$ \\
\hline 076-100 & A05 \\
\hline $101-125$ & A06 \\
\hline $126-150$ & A07 \\
\hline $151-175$ & A06 \\
\hline $176-200$ & A09 \\
\hline $201-225$ & A010 \\
\hline $226-250$ & A011 \\
\hline $251-275$ & $\wedge 012$ \\
\hline $276-300$ & A013 \\
\hline
\end{tabular}


LUNG-CLEARANCE CLASSIFICATION

OF RADIONUCLIDES IN CALCINED

PHOSPHATE ROCK DUST

D. R. Kalkwarf

P. 0. Jackson

August 1984

Prepared for the U.S. Environmental Protection Agency under a Related Services Agreement with the U.S. Department of Energy Contract DE-AC06-76RLO 1830

Pacific Northwest Laboratory

Richland, Washington 99352 


\section{SUMMARY}

Lung-clearance classifications for $210 \mathrm{pb}$ and $210 \mathrm{po}$ in airborne dust from elemental phosphorus plants were estimated for use with the lung clearance model proposed by the ICRP Task Group on Lung Dynamics. Estimates were based on measurements of dissolution rates for these radionuclides from sized dust samples into simulated lung fluid at $37^{\circ} \mathrm{C}$. The estimates were expressed in the classification terms of the model, i.e., $D, W$ and $Y$, indicating lung clearance half-times of 0 to 10 days, 11 to 100 days and more than 10D days. Dust samples were obtained from two plants in the western United States, and dissolution trials were conducted on fractions containing particles with aerodynamic equivalent diameters (AED) of 0 to $3 \mu \mathrm{m}$ and of 3 to $10 \mu \mathrm{m}$. The ${ }^{210_{\mathrm{Pb}}}$ and $210 \mathrm{Po}$ in each of these fractions were classified $100 \%$ Class $Y$. The specific activities of both radionuclides increased with decreasing AED of the particles. 


\section{CONTENTS}

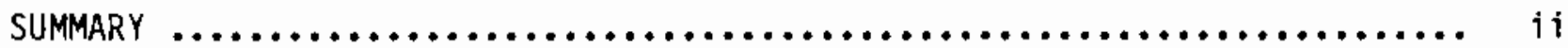

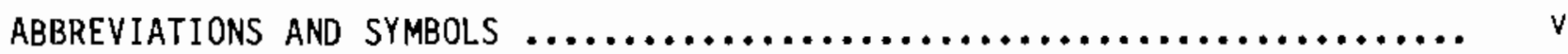

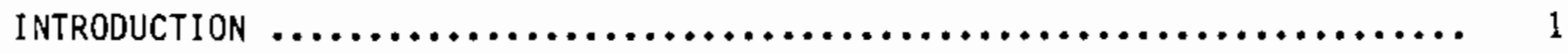

CONCLUSIONS AND RECOMMENDATIONS $\ldots \ldots \ldots \ldots \ldots \ldots \ldots \ldots \ldots \ldots \ldots \ldots \ldots \ldots, 2$

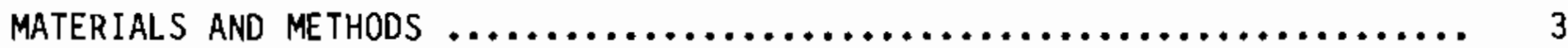

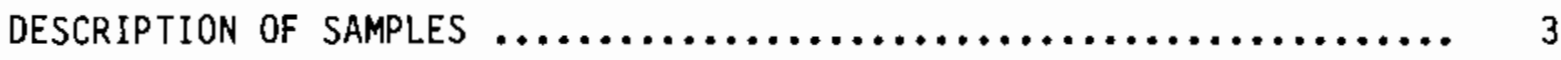

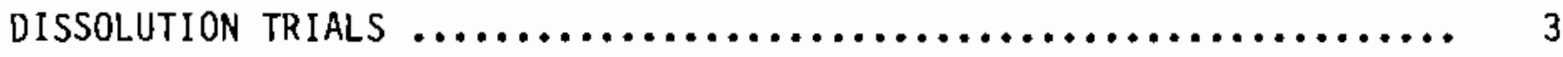

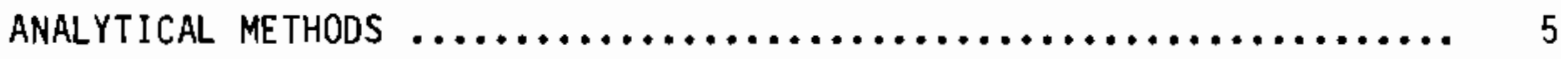

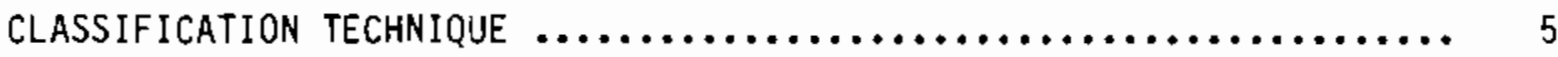

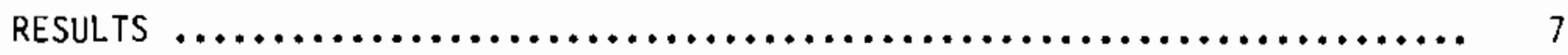

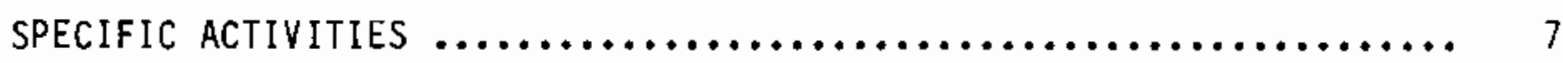

DISSOLUTION TRIALS AND CLASSIFICATIONS $\ldots \ldots \ldots \ldots \ldots \ldots \ldots \ldots \ldots \ldots, 8$

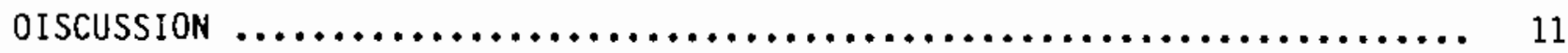

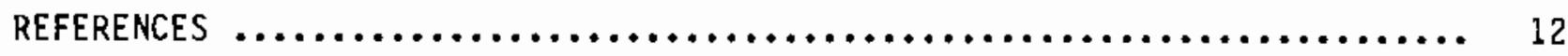

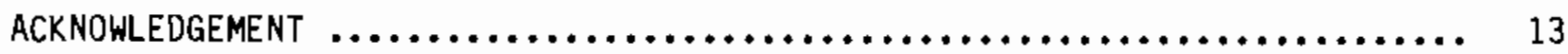




\section{FIGURES}

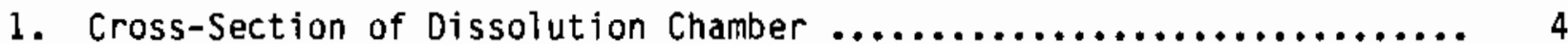

\section{$\underline{\text { TABLES }}$}

1. Specific Activities of $21 \mathrm{D}_{\mathrm{Pb}}$ and $210_{\mathrm{po}}$ in the Dust Samples at Their collection Time

2. Dissolution Pattern of $210 \mathrm{~Pb}$ and $210 \mathrm{po}$ from Dust Samples

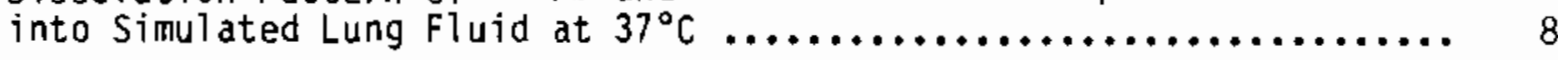

3. Comparison of $210 \mathrm{~Pb}$ and $210 \mathrm{Po}$ Activities in Particles at the Beginning and End of Their Dissolution Trials

4. Dissolution Parameters for ${ }^{210} \mathrm{~Pb}$ and $210 \mathrm{Po}$ in the Dust Samples ...... 10 


\section{LIST OF ABBREVIATIONS AND SYMBOLS}

ABBREVIATIONS

AED - aerodynamic equivalent diameter

${ }^{\circ} \mathrm{C}$ - degrees Celcius

ICRP - International Commission on Radiological Protection

meq/L - milliequivalents per liter

$\mathrm{mL} \quad$ - milliliters

SLF - simulated liquid fluid

$\mu \mathrm{m} \quad$ - micrometers

SYMBOLS

$210 \mathrm{pb}$ - lead isotope with atomic mass 210

210 Po - polonium isotope with atomic mass 210 


\section{INTRODUCTION}

Uranium, thorium and their radioactive decay products are present at low concentrations in minerals used to produce elemental phosphorus (Roessier et a1. 1979, Johnson et al. 1980). When these minerals are calcined, component radionuclides that can form volatile compounds at the high temperatures of the kiln evaporate and, on cooling, condense on any available surface. Part of this condensation occurs on airborne dust passing out of the kiln stack; and since the smaller particles generally have the highest specific surface area, volatile radionuclides are expected to concentrate on them. In particular $210 \mathrm{pb}$ and $210 \mathrm{Po}$, have been reported to concentrate on the smaller particles of coal fly ash (Mc8ride et a1. 1978, Kalkwarf et a1. 1984). Also, small particles are deposited efficiently in the lungs; and if radioactive, they may pose a source of radiation damage to persons exposed to this dust (Miller et a1. 1979).

The radiation dosimetry for radionuclides deposited in the lungs can be evaluated with the aid of the lung-clearance model proposed by the Task Group on Lung Dynamics of the International Commission on Radiological Protection (ICRP Task Group on Lung Dynamics 1966). Use of this model requires clearancerate classifications for the radionuclides, and three categories are used: $D$, $W$ and $Y$, corresponding to $l$ ung $c l$ earance half-times of 0 to 10 days, 11 to 100 days and greater than 100 days, respectively.

This study was conducted at the request of the U.S. Environmental Protection Agency to estimate the lung-clearance classifications for $210 \mathrm{~Pb}$ and $210 \mathrm{Po}$ in airborne dust from el emental phosphorus plants. Clearance-rate classifications were estimated by measuring dissolution half-times of the radionuclides from sized dust samples into simulated lung fluid at $37^{\circ} \mathrm{C}$, the normal temperature of the human body. The rationale for this approach has been discussed el sewhere (Kalkwarf et al. 1984). Samples from the FMC plant, Pocatello, Idaho, and from the Stauffer Chemical Corporation plant, Silver Bow, Montana, were analyzed. Dissolution trials were conducted on sample fractions containing particles with aerodynamic equivalent diameters in the ranges 0 to $3 \mu m$ and 3 to $10 \mu m$, because such particles are deposited most efficientily in the lungs. 


\section{CONCLUSIONS AND RECOMMENDATIONS}

The dissolution rates of $210 \mathrm{~Pb}$ and $210 \mathrm{Po}$ in samples from both the $\mathrm{FMC}$ and Stauffer plants were very similar, and very slow. It is recommended that both $210 \mathrm{~Pb}$ and $210 \mathrm{Po}$ be considered $100 \%$ Class $\mathrm{Y}$ substances for calculations with the ICRP Lung-Clearance Model. 
MATERIALS AND METHODS

\section{DESCRIPTION OF SAMPLES}

The samples of phosphate rock dust were received from Radian Corporation, Research Triangle Park, North Carolina 27709. They had been collected by Radian personnel at the FMC plant in Pocatello, Idaho, on October 27, 1983 and at the Stauffer Chemical Corporation plant, Silver Bow, Montana on November 10, 1983. These samples were collected in the off-gas streams from the calciners prior to their entry into wet scrubber units, because the dust loadings in the streams at these points were relatively high. A Source Assessment Sampling System (SASS) was used to collect the samples (Blake 1978). This system separated the samples into fractions containing particles with aerodynamic equivalent diameters (AED) in the size ranges of 0 to $1 \mu \mathrm{m}, 1$ to $3 \mu \mathrm{m}, 3$ to $10 \mu \mathrm{m}$, and greater than $10 \mu \mathrm{m}$. The fractions were dried and weighed by Radian personnel and mailed to the Pacific Northwest Laboratory (PNL). In order to obtain sufficient amounts of material for the dissolution trials at PNL, fractions with particles in the two smaller size ranges were combined in the same proportions by weight as were obtained in the original collections.

\section{DISSOLUTION TRIALS}

The dissolution trials were conducted on dust fractions containing particles with AED's in the ranges: 0 to $3 \mu \mathrm{m}$ and 3 to $10 \mu \mathrm{m}$. A $0.5000-g$ portion of dust was weighed and placed in a 10-mL glass vial with a conical bottom and a Teflon-lined, screw cap (Reacti-Vial, Pierce Chemical Co., Rockford, IL). The vial and contents were placed in an aluminum constant-temperature block (Reacti-Therm, Pierce Chemical Co.) maintained at $37^{\circ} \mathrm{C}$ and equipped with a magnetic stirrer. A 5-mL portion of simulated lung fluid (SLF) was added to the vial together with a Teflon-coated triangular magnetic bar to suspend the particles in the SLF. This assembly is shown in Figure 1. The composition of the SLF has already been published (Moss 1979) and closely resembles that of human interstitial fluid. After one day, the suspension was filtered, and the particles were resuspended in $5 \mathrm{~mL}$ of fresh SLF for an additional time period. This procedure was repeated at selected times for a total period of 60 days. 


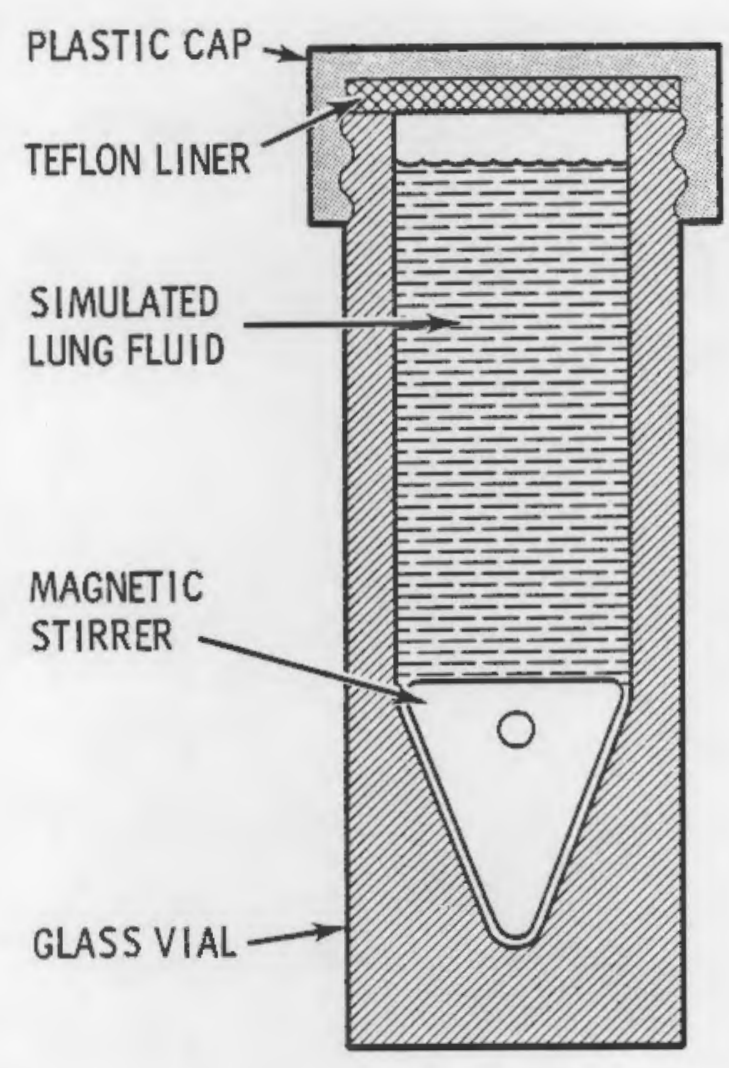

\section{FIGURE 1. Cross-Section of Dissolution Chamber}

The $\mathrm{pH}$ 's of the suspensions were tested every three days and, if necessary, readjusted to within the range 7.3 to 7.4 by addition of small volumes of hydrochloric acid. The filtration operation consisted of several steps. First the suspension was centrifuged in the vial to pack most of the particles into the conical bottom. The supernatant liquid was then filtered through a $13-\mathrm{mm}$ diameter membrane filter (Millipore GS) with a 0.22- m pore size. Particles adhering to the filter were washed back into the dissolution vial with $5 \mathrm{~mL}$ of fresh SLF. A detailed description of this technique has been published elsewhere (Kalkwarf 1983). The filtered samples of SLF were stored in glass screwcapped vials until they were analyzed. At the end of the 60-day dissolution period, the residual particles were also transferred to glass screw-capped vials for analysis. 
ANALYTICAL METHODS

Samples of the original dust fractions, the filtered solutions from the dissolution trials and the undissolved particles remaining after the dissolution trials were analyzed for $210 \mathrm{~Pb}$ and $210_{\mathrm{Po}}$. The specific activities of $210 \mathrm{pb}$ in the solid samples were measured with a high-resolution, intrinsicgermanium, gamma-ray spectrometer. The samples were placed in small plastic vials for analysis, and the measurements were calibrated with 210 pb-spiked soil samples packed in the same geometry.

Measurement of the specific activities of $210_{P_{0}}$ in the solid samples required dissolution of the particles in mixtures of perchloric, nitric, hydrofluoric and hydrochioric acids. 210 po activity was measured by alpha counting after deposition of the polonium on a silver disc (Jackson and Thomas 1981). In order to correct for the radiochemical yield and counter efficiency, a measured quantity of ${ }^{208}$ Po was added to each sample prior to dissolution; and the ratio of the activities of ${ }^{208} \mathrm{Po}_{\mathrm{O}}$ and ${ }^{210} \mathrm{Po}_{\mathrm{o}}$ were measured on an alpha-particle spectrometer with a silicon surface-barrier diode.

The activities of $210 \mathrm{~Pb}$ and $210 \mathrm{Po}$ in the SLF solutions were determined following their sequential chemical separation (Jackson and Thomas 1981). The portion containing the separated $210 \mathrm{~Pb}$ was allowed to stand for about two months to allow ingrowth of $210 \mathrm{Po}$, and both portions were analyzed for $210^{P_{0}}$ as described in the preceding paragraph. The specific activities of $210_{\mathrm{Pb}}$ were calculated from the ${ }^{210} \mathrm{Po}_{\mathrm{o}}$ alues using the appropriate radioactive ingrowth equations.

\section{CLASSIFICATION TECHNIQUE}

The lung-clearance model proposed by the ICRP Task Group on Lung Dynamics assumes that the fraction of radionuclide remaining in the lungs can be expressed as an exponential function of time. If a radionuclide is present in more than one physical or chemical form and dissolution is the dominant clearance pathway, a sum of exponential terms is generally required to express the fraction remaining undissolved. Therefore, data from the dissolution trials were fitted to equations of the form: 


$$
F=\sum_{i} f_{i} \exp \left(-0.693 t / T_{i}\right)
$$

where $F$ is the fraction of radionuclide remaining undissolved after time $t$, and the $f_{i}$ are the initial weight fractions of the various forms of this radionuclide with dissolution half-times $T_{j}$. The values of $F$ were calculated by subtracting the amount of radionuclide dissolved during any sampling period from the amount undissolved at the beginning of that period and dividing this quantity by the initial amount of radionuclide in the sample. The latter quantity was measured by analysis of a separate portion of sample and was verified by summing the amounts of dissolved and undissolved radionuctide during the dissolution trial. Values of $f_{i}$ and $T_{i}$ were obtained by graphical analysis of the data. The lung-clearance half-time of the radionuclide was then assumed to be equal to its dissolution half-time in simu? ated lung fluid. 


\section{RESULTS}

SPECIFIC ACTIVITIES

The specific activities of ${ }^{210} \mathrm{~Pb}$ and $210 \mathrm{Po}$ in the dust samples at the time of their collection at the stacks are listed in Table 1. The values have been corrected for radioactive decay of $210 \mathrm{~Pb}$ and radioactive bujld-up and decay of 210 po between the collection time and the time of analysis. Samples collected at the FMC plant were designated by the prefix, FMC; and those collected at the Stauffer Chemical Corporation plant were designated with the prefix, SCC.

TABLE 1. Specific Activities of $210 \mathrm{~Pb}$ and $210_{\mathrm{Po}}$ in the Dust Samples at the Collection Times ( $95 \%$ confidence intervals)

\begin{tabular}{|c|c|c|}
\hline $\begin{array}{c}\text { Sample } \\
\text { Designation }\end{array}$ & $\begin{array}{l}\text { Specjific Activity } \\
\text { of } 210 \mathrm{~Pb}(\mathrm{pC} i / g) \\
\end{array}$ & $\begin{array}{l}\text { Specjific Activity } \\
\text { of } 210 \text { Po (pCi/g) } \\
\end{array}$ \\
\hline FMC, $0-3) m$ & $(6.7 \pm 0.6) \times 10^{2}$ & $(9.5 \pm 0.6) \times 10^{4}$ \\
\hline FMC, 3-10 im & $39 \pm 4$ & $(3.9 \pm 0.2) \times 10^{3}$ \\
\hline $\mathrm{FMC},>10 \mathrm{~mm}$ & $21 \pm 2$ & $(2.4 \pm 0.2) \times 10^{2}$ \\
\hline $\mathrm{scc}, 0-3 \mathrm{~mm}$ & $(3.8 \pm 0.3) \times 10^{3}$ & $(2.0 \pm 0.2) \times 10^{3}$ \\
\hline$S C C, 3-10, m$ & $(3.5 \pm 0.3) \times 10^{3}$ & $(1.6 \pm 0.2) \times 10^{3}$ \\
\hline $\mathrm{SCC},>10 \mathrm{~m}$ & $(4.7 \pm 0.1) \times 10^{2}$ & $(1.4 \pm 0.1) \times 10^{3}$ \\
\hline
\end{tabular}

The specific activities of $210 \mathrm{~Pb}$ and $210 \mathrm{Po}$ were found to increase with decreasing $A E D$ of the particles, but this effect was more pronounced at the $F M C$ plant.

It is important to be aware that the distribution of radionuclides by particle-size range as shown in Table 1 is representative only of the distribution of radionuclides which are associated with particles in the off-gas streams at the locations sampled. Because of the relatively high temperatures $\left(250-350^{\circ} \mathrm{C}\right)$ of the off-gas streams at the scrubber inlet sampling locations, some of the ${ }^{210}$ Po may still have been in the vapor state (i.e., not condensed onto particles) and therefore not collected by the SASS train. This may explain the large differences in the specific activities of 210 Po in the 0 to 3 im fractions from the FMC and Stauffer plants. More detailed information on 
the particle size distribution of these radionuclides in calciner off-gas streams is presented in EPA's emission test reports for these plants (EPA Office of Radiation Programs 1984a, 1984b).

OISSOLUTION TRIALS ANO CLASSIFICATIONS

The results of the dissolution trials on the dust samples are shown in Table 2. Values for the specific activity of $210 \mathrm{~Pb}$ in the samples at the start

TABLE 2. Dissolution Pattern of $210_{\mathrm{Pb}}$ and $210_{\mathrm{Po}}$ from Oust Samples into Simulated Lung Fluid at $37^{\circ} \mathrm{C}$

\begin{tabular}{|c|c|c|c|c|}
\hline Sample & $\begin{array}{r}\text { Initial }{ }^{210} \mathrm{Po}_{0} \\
\text { Activity }(\mathrm{pCi} / \mathrm{g}) \\
\end{array}$ & $\begin{array}{l}\text { Dissolution } \\
\text { Iime (days) }\end{array}$ & $\begin{array}{l}210_{\mathrm{Pb} \text { raction of }} \\
\text { Undissolving } \\
\end{array}$ & $\begin{array}{c}21 \bar{b}_{\text {po Remaining }} \\
\text { Undissolved } \\
\end{array}$ \\
\hline FMC, $0-3 \mu m$ & $(8.5 \pm 0.5) \times 10^{4}$ & $\begin{array}{r}1.0 \\
3.0 \\
10.0 \\
20.2 \\
37.0 \\
59.0\end{array}$ & $\begin{array}{l}0.9984 \\
0.9973 \\
0.9968 \\
0.9962 \\
0.9956 \\
0.9950\end{array}$ & $\begin{array}{l}0.9997 \\
0.9990 \\
0.9984 \\
0.9980 \\
0.9979 \\
0.9978\end{array}$ \\
\hline$F M C, 3-10 \mu \pi$ & $(3.6 \pm 0.2) \times 10^{3}$ & $\begin{array}{r}1.0 \\
3.0 \\
10.0 \\
20.2 \\
37.0 \\
59.0\end{array}$ & $\begin{array}{l}0.9933 \\
0.9744 \\
0.9682 \\
0.9618 \\
0.9554 \\
0.9490\end{array}$ & $\begin{array}{l}0.9991 \\
0.9988 \\
0.9979 \\
0.9970 \\
0.9943 \\
0.9914\end{array}$ \\
\hline $\mathrm{SCC}, 0-3 \mu \mathrm{m}$ & $(1.8 \pm 0.2) \times 10^{3}$ & $\begin{array}{r}1.0 \\
2.9 \\
8.9 \\
20.8 \\
40.8 \\
59.0\end{array}$ & $\begin{array}{l}0.9999 \\
0.9999 \\
0.9994 \\
0.9991 \\
0.9983 \\
0.9978\end{array}$ & $\begin{array}{l}0.9997 \\
0.9996 \\
0.9989 \\
0.9986 \\
0.9981 \\
0.9980\end{array}$ \\
\hline SCC, 3-10 $\mu \mathrm{m}$ & $(1.3 \pm 0.2) \times 10^{3}$ & $\begin{array}{r}1.0 \\
2.9 \\
8.9 \\
20.8 \\
40.8 \\
59.0\end{array}$ & $\begin{array}{l}1.0000 \\
0.9999 \\
0.9990 \\
0.9991 \\
0.9985 \\
0.9979\end{array}$ & $\begin{array}{l}0.9997 \\
0.9993 \\
0.9992 \\
0.9948 \\
0.9942 \\
0.9940\end{array}$ \\
\hline
\end{tabular}


of the dissolution trials were essentially the same as those listed in Table 1 , due to the long, 20-year half-life of this radionuclide. However, the specific activities of $210_{0}$ in the samples changed between the collection time and the start of the dissolution triais due to the combined effects of radioactive build-up and decay. The specific activities of $210 \mathrm{po}_{\mathrm{o}}$ at the start of the dissolution trials are listed in Table 2. As can be seen from Table 2, very iittle $210 \mathrm{~Pb}$ or $210_{\mathrm{Po}}$ were dissolved during the 60 -day period of the trials.

The insolubilities of $210 \mathrm{pb}$ and $210 \mathrm{po}$ were also tested by comparing their measured specific activities in the solid residues at the end of the dissolution trials with those predicted if no dissolution of these radionuclides had occurred. Such a test was considered desireable since the inability to detect significant amounts of $210 \mathrm{~Pb}$ and $210 \mathrm{Po}$ in the filtrates might have been due to deposition of these radionuclides on the filters or on the walls of the dissolution chamber. The results are shown in Table 3 and tend to confirm the insolubilities of $210 \mathrm{~Pb}$ and $210_{\mathrm{Po}}$ in simulated lung fluid at $37^{\circ} \mathrm{C}$. These data were not used to determine the dissolution rates for the radionuclides because the amounts dissolved would appear as small, imprecise differences between two large numbers.

TABLE 3. Comparison of $210 \mathrm{~Pb}$ and $210 \mathrm{Po}$ Activities in Particles at the Beginning and End of Their Dissolution Trials (95\% confidence intervals)

\begin{tabular}{|c|c|c|c|c|}
\hline Sample & $\begin{array}{c}\text { Inltiol } 210 \mathrm{~Pb} \\
\text { Activity }(\mathrm{pCl} / \mathrm{g})\end{array}$ & $\begin{array}{c}\text { Final }{ }^{210} \mathrm{~Pb} \\
\text { Activity (pCI/g) }\end{array}$ & $\begin{array}{r}\text { Initial } 210 \mathrm{Po}_{0} \\
\text { Activity }(\mathrm{pCl} / \mathrm{g})\end{array}$ & $\begin{array}{c}\text { Final }{ }^{210} \mathrm{Po}^{*} \\
\text { Activity }(\mathrm{pCi} / \mathrm{g})\end{array}$ \\
\hline $\begin{array}{l}\text { FMC, } 0-3 \mu \mathrm{m} \\
\text { FMC, } 3-10 \mu \mathrm{m}\end{array}$ & $\begin{array}{l}(6.7 \pm 0.6) \times 10^{2} \\
39 \pm 4\end{array}$ & $\begin{array}{l}(6.2 \pm 0.2) \times 10^{2} \\
42 \pm 18\end{array}$ & $\begin{array}{l}(8.5 \pm 0.5) \times 10^{4} \\
(3.6 \pm 0.2) \times 10^{3}\end{array}$ & $\begin{array}{l}(8.5 \pm 1.7) \times 10^{4} \\
(3.0 \pm 0.4) \times 10^{3}\end{array}$ \\
\hline $\mathrm{scc}, 0-3 \mu \mathrm{m}$ & $(3.8 \pm 0.3) \times 10^{3}$ & $(3.4 \pm 2.0) \times 10^{3}$ & $(1.8 \pm 0.2) \times 10^{3}$ & $(1.2 \pm 0.9) \times 10^{3}$ \\
\hline $5 C C, 3-10 \mu m$ & $(3.5 \pm 0.3) \times$ & $(3.1 \pm 1.6) \times 10^{3}$ & $(1.3 \pm 0.2) \times 10^{3}$ & $(0.7 \pm 0.9) \times 10^{3}$ \\
\hline
\end{tabular}

* Corrected to the starting tIme of the trial.

The data listed in Table 2 were analyzed graphically to obtain the dissolution parameters for Equation 1 and the values are listed in Table 4. From these data, it was conciuded that both $210 \mathrm{~Pb}$ and $210 \mathrm{Po}$ should be considered $100 \%$ Class $Y$ for calculations with the ICRP Lung-Clearance Model. 
TABLE 4. Dissolution Parameters for $210 \mathrm{pb}$ and $210 \mathrm{po}_{\mathrm{o}}$ in the Dust Samples

\begin{tabular}{|c|c|c|c|c|}
\hline Sample & $\mathrm{f}$ & $210 p_{b} T$ (days) & $\mathrm{f}$ & $210 p_{0} T$ (days) \\
\hline FMC, $0-3, \mathrm{~m}$ & 1.00 & $8 \times 10^{3}$ & 1.00 & $2 \times 10^{4}$ \\
\hline$F M C, 3-10 \mathrm{~lm}$ & 1.00 & $8 \times 10^{2}$ & 1.00 & $5 \times 10^{3}$ \\
\hline SCC, $0-3) m$ & 1.00 & $2 \times 10^{4}$ & 1.00 & $2 \times 10^{4}$ \\
\hline SCC, 3-10 $\mathrm{sm}$ & 1.00 & $2 \times 10^{4}$ & 1.00 & $7 \times 10^{3}$ \\
\hline
\end{tabular}




\section{DISCUSSION}

The slow dissolution rates of $210 \mathrm{pb}$ and $210 \mathrm{po}$ from calcined phosphate rock dust into SLF are similar to those reported for these radionuclides in uraniummill tailings and coal fly ash (Kalkwarf 1979, Kalkwarf et al. 1984). The chemical forms of $210 \mathrm{~Pb}$ and $210 \mathrm{Po}$ in these materials are not known; but even if they were present in water-soluble forms, they would probably be transformed rapidly in SLF to insoluble carbonates or hydrous oxides. The concentration of bicarbonate jon in the SLF was $31 \mathrm{meq} / \mathrm{L}$, and the pH was 7.3 to 7.4 (Moss 1979 ). 


\section{REFERENCES}

Blake, D. E. 1978. Source Assessment Sampling System: Design and Development. U.S. Environmental Protection Agency Report EPA-600/7-78-018, National Technical Information Service, Springfield, Virginia.

EPA Office of Radiation Programs. 19B4a. Emissions of Lead-210 and Polonium210 from Calciners at Elemental Phosphorus Plants: FMC Plant, Pocatello, Idaho. U.S. Environmental Protection Agency, Washington, D.C. 20460.

EPA Office of Radiation Programs. 1984b. Emissions of Lead-210 and Polonium210 from Calciners at Elemental Phosphorus Plants: Stauffer Plant, Silver Bow, Montana. U.S. Environmental Protection Agency, Washington, D.C. 20460.

ICRP Task Group on Lung Dynamics. 1966. "Deposition and Retention Models for Internal Dosimetry of the Human Respiratory Tract." Health Phys. $12: 173-207$.

Jackson, P. 0. and C. W. Thomas. 1981. An Investigation of the Degree of Equilibrium of the Long-Lived Uranium-238 Decay Chain Members in Airborne and Bulk Uranium Ore Dusts. U.S. Nuclear Regulatory Commission Report, NUREG/CR-1895, National Technical Information Service, Springfield, Virginia.

Johnson, R., C. M. Wai, B. McVeety, H. Lee and H. Willmes, 1980. "Uranium in Soil Around Phosphate Processing Plants in Pocatello, Idaho". Bull. Environ. Contam. Toxicol. 24(5):735-738.

Kalkwarf, D. R. 1979. Solubility Classification of Airborne Products from Uranium Ores and Tailings Piles. U.S. Nuclear Regulatory Commission Report, NUREG/CR-0530, National Technical Infomation Service, Springfield, Virginia.

Kalkwarf, D. R. 1983. "Dissolution Rates of Uranium in Simulated Lung Fluid." Sci. Total Environ. 28:405-414.

Kalkwarf, D. R., P. O. Jackson and J. M. Hardin. 1984. "Lung-Clearance Classification of Radionuclides in Coal Fiy Ash." Health Phys. (In press).

Moss, 0. R. 1979. "Simulants of Lung Interstitial Fluid". Health Phys. $36: 447-448$.

Roessler, C. E., Z. A. Smith, W. E. Bolch and R. J. Prince. 1979. "Uranium and Radium-226 in Florida Phosphate Materials." Health Phys. 37(3):269-277. 
ACKNOWLEDGEMENT

The authors wish to acknowledge the careful work of G. Brodaczynski and C. Veverka, Jr. in preparing and analyzing the samples for this study. 


\section{DISTRIBUTION}

No. of

Copies

OFFSITE

50 P. Magno

Environmental Standards Branch

Office of Radiation Programs

U.S. Environmental Protection Agency

Washington, DC 20460

27 DOE Technical Information Center
No. of

Copies

ONSITE

DOE Richland Operations Office

H. E. Ransom

19 Pacific Northwest Laboratory

P. 0. Jackson (5)

D. R. Kalkwarf (5)

R. S. Schirmer

N. A. Wogman

Publishing Coordination (2)

Technical Information (5) 